\title{
Small-angle neutron scattering investigation of polyurethane aged in dry and wet air
}

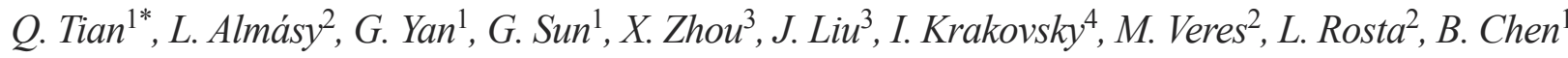 \\ ${ }^{1}$ Key Laboratory of Neutron Physics and Institute of Nuclear Physics and Chemistry, China Academy of Engineering \\ Physics (CAEP), 621999 Mianyang, China \\ ${ }^{2}$ Wigner Research Centre for Physics, Institute for Solid State Physics and Optics, P.O.Box 49, H-1525 Budapest, Hungary \\ ${ }^{3}$ Institute of Chemical Materials, CAEP, 621999 Mianyang, China \\ ${ }^{4}$ Department of Macromolecular Physics, Faculty of Mathematics \& Physics, Charles University, V Holešovičkách 2 , \\ 18000 Praha 8, Czech Republic
}

Received 14 September 2013; accepted in revised form 27 December 2013

\begin{abstract}
The microstructures of Estane 5703 aged at $70^{\circ} \mathrm{C}$ in dry and wet air have been studied by small-angle neutron scattering. The samples were swollen in deuterated toluene for enhancing the contrast. The scattering data show the characteristic domain structure of polyurethanes consisting of soft and hard segments. Debye-Anderson-Brumberger function used with hard sphere structure factor, and the Teubner-Strey model are used to analyze the two-phase domain structure of the polymer. The combined effects of temperature and humidity have a strong disruption effect on the microstructures of Estane. For the sample aged at $70^{\circ} \mathrm{C}$ in wet air for $1 \mathrm{month}$, the domain size, described by the correlation length, increases from 2.3 to $3.8 \mathrm{~nm}$ and their distance, expressed by hard-sphere interaction radius, increases from 8.4 to $10.6 \mathrm{~nm}$. The structure development is attributed to degradation of polymer chains as revealed by gel permeation chromatography. The hydrolysis of ester links on polymer backbone at $70^{\circ} \mathrm{C}$ in the presence of water humidity is the main reason for the changes of the microstructure. These findings can contribute to developing predictive models for the safety, performance, and lifetime of polyurethanes.
\end{abstract}

Keywords: material testing, SANS, Estane 5703, polyurethane, aging

\section{Introduction}

Polyurethanes (PUs) are a very attractive type of segmented polymers with unique mechanical properties derived from thermodynamic incompatibility between flexible soft segments (SSs) and covalently attached hard segments (HSs). They have important applications, such as surface coatings and sealants, high performance adhesives, durable elastomeric wheels and tires, rigid foam insulation panels, blood contact medical devices and shape memory materials [1]. PUs are usually intended for long-term use. In general, the mechanical properties of PUs are highly dependent on the microstructural changes induced by extended exposure to various agents, such as temperature, humidity, and irradiation.

The subject of this work is a commercial segmented PU with low HS content, known as Estane 5703. It is incorporated into high explosive formulations to impart structural integrity to the composite and to decrease its sensitivity to undesired stimuli. Mang et al. [2] revealed that Estane mixed with nitroplasticizer has a significant change of microstructures after aging for 1.5 months at $70^{\circ} \mathrm{C}$. Orler et al. [3] found that Estane 5703 aged at $70^{\circ} \mathrm{C}$ in dry air quickly restored its initial mechanical properties, while the mechanical properties of the samples aged at $70^{\circ} \mathrm{C}$

\footnotetext{
*Corresponding author, e-mail: tqsuperego@163.com

(C) BME-PT
} 
in wet air only partially recovered with time. Since Estane 5703 strongly affects the mechanical properties of the composites, it is essential to know how the material changes with time at various environmental conditions. Small-angle scattering technique is a very powerful tool for investigating internal structures of PUs [2, 4-9]. Mang and coworkers [2, 9] applied small-angle neutron scattering (SANS) technique to determine the domain structures in deuterated Estane with low HS content. To the best of our knowledge, there is little information on nanoscale structural changes in Estane aged at different temperature and humidity conditions.

Our motivation is to reveal the influence of aging on the microstructures of Estane by applying a scattering method, which is a direct probe of the structure on the nanometer length scales. These results will aid in understanding the structure-property correlations, as well as the development of predictive models for the safety, performance, and lifetime of polyurethanes.

\section{Experimental section}

\subsection{Materials}

Estane 5703 obtained as pellets from the Lubrizol Advanced Materials, Inc., US, contains about $23 \mathrm{wt} \%$ HSs. The SSs are polymers (oligomers) of the ester of adipic acid with 1,4 butanediol; they have an average molecular weight in the range of 800 to $1050 \mathrm{Da}$ [9]. The HSs consist of very short polyurethanes made from 4,4'-diphenylmethane diisocyanate molecules bonded together by urethane links to the butanediol that serve as chain extenders, as shown in Figure 1.

Estane pellets were compression-molded into $1 \mathrm{~mm}$ thick disk at $20 \mathrm{MPa}, 120^{\circ} \mathrm{C}$ for 10 minutes and then cooled to room temperature $(R T)$, initiating the phase separation process. The Estane samples (10× $10 \times 1 \mathrm{~mm}$ ) were sealed in containers to maintain the wet and dry environments. Water for $100 \%$ relative humidity $(R H)$ condition and silica gel desiccant for dry condition were employed inside the sealed containers. The sealed containers were placed at $R T$ and $70^{\circ} \mathrm{C}$ for 1 and/or 2 months. All the aged samples were allowed to equilibrate at $R T$ for not less than 3 months. The samples were swollen by deuter-

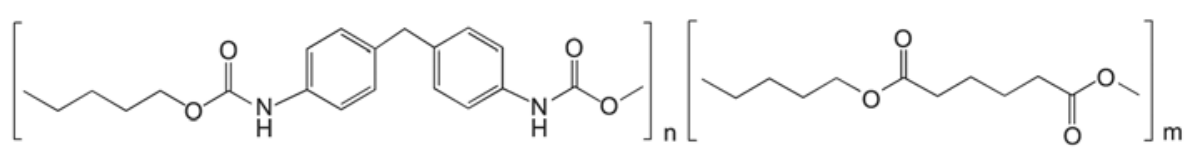

Figure 1. Molecular structure of Estane 5703 ated toluene for 48 hours before SANS measurements in order to reach equilibrium swelling and enhance the scattering contrast between HS and SS domains, and were measured in the swollen state.

\subsection{Characterization}

The SANS measurements were performed with the small-angle neutron scattering diffractometer 'Yellow Submarine' at the Budapest Research Reactor. A mean neutron wavelength of 0.47 and $1.175 \mathrm{~nm}$ was selected by mechanical velocity selector. The sample-detector distance was 1.57 and $5.50 \mathrm{~m}$ respectively. By changing the wavelength and sampledetector distance, we have covered a $q$ range of $0.08-2.5 \mathrm{~nm}^{-1}$. The acquisition times were $30 \mathrm{~min}-$ utes for each sample at each detector position. Immediately before the measurements, the swollen samples were transferred into quartz cells of path length $2 \mathrm{~mm}$ and filled with deuterated toluene (Figure 2). The scattering data were processed using BerSANS software [10]. The data reduction corrects the raw measured data for the contributions of the background, transmission, scattering from empty cell and normalizes the data to the efficiency of the individual cells of the multidetector.

The gel permeation chromatography (GPC) measurements were performed using a Biospher GMB 100 column $(8 \times 500 \mathrm{~mm}$, Labio, Czech Republic) filled with $10 \mu \mathrm{m}$ sorbent particles. Tetrahydrofuran (Sigma-Aldrich), distilled and dried over molecular sieves ( $4 \AA$ ), was used as a mobile phase at a flow rate $1 \mathrm{~mL} / \mathrm{min}$. Small amount of toluene $(2 \%(\mathrm{w} / \mathrm{v}))$

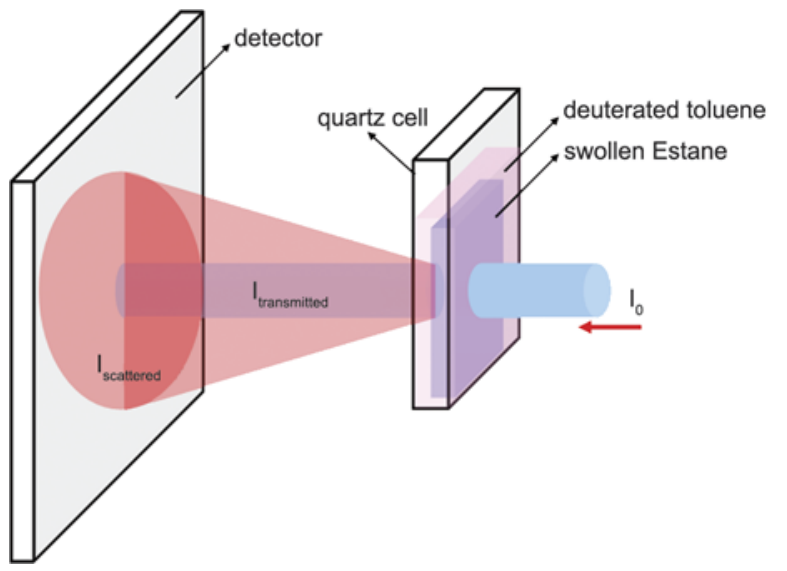

Figure 2. Schematic diagram of the SANS measurements of swollen Estane 
was used as internal standard. The data from a refractive index detector were collected and treated by using CSW 1.7 software (Data Apex, Czech Republic). For the determination of molar masses, a universal calibration equation calculated from the data on polystyrene standards (Polymer Standards Service) was used.

\subsection{Data analysis}

Polyurethanes containing $40 \%$ or less HSs (by weight) are known to have a discrete hard microdomain structure [4]. A broad peak seen in all data (Figures 3 and 4) confirms that this is the case in the studied samples. In the simplest approximation, the peak position $\left(q_{0}\right)$ gives the average distance between the domains as $d=2 \pi / q_{0}$. It can be seen, that with aging, the peak shifts to lower $q$ values, indicating the increase of the interdomain distance. To extract more information, the SANS scattering data are usually analyzed by fitting parameters of model functions to the data, provided that appropriate models are known for the investigated structure. In the present case, the simplest plausible model of domains in a matrix was the ensemble of hard spheres with spatial distribution according to hard sphere interaction potential. However, such model did not give adequate fits, even when enhancing the model to include polydispersity, or using different hard sphere and interaction radii. Such results were not unexpected, given the hard domains do not necessarily have compact shapes and smooth interfaces. For a similar polymer containing hard domains in a soft matrix, Krakovsky and coworkers [5, 6] found empirically

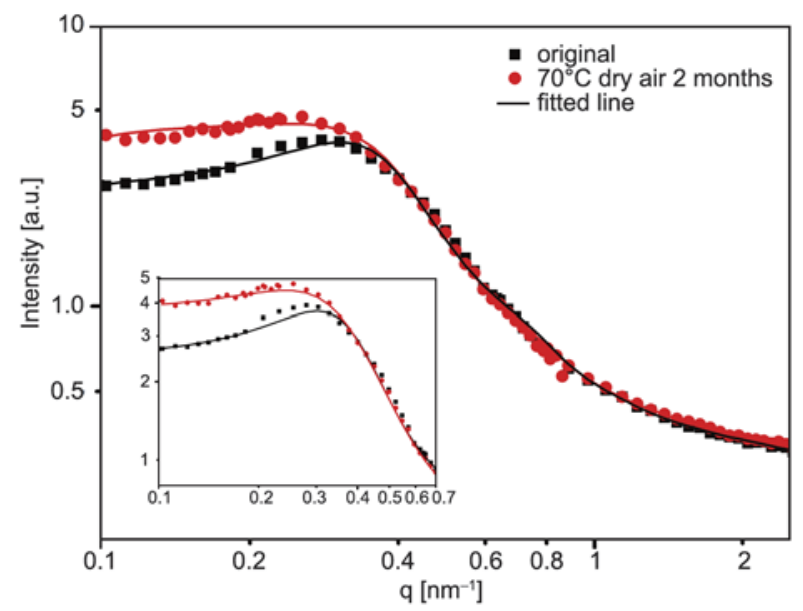

Figure 3. SANS data of the original Estane and aged Estane at $70^{\circ} \mathrm{C}$ in dry air for 2 months, the solid lines are the fitting results by DAB-PY model. The inset shows the fitting results by TS model.

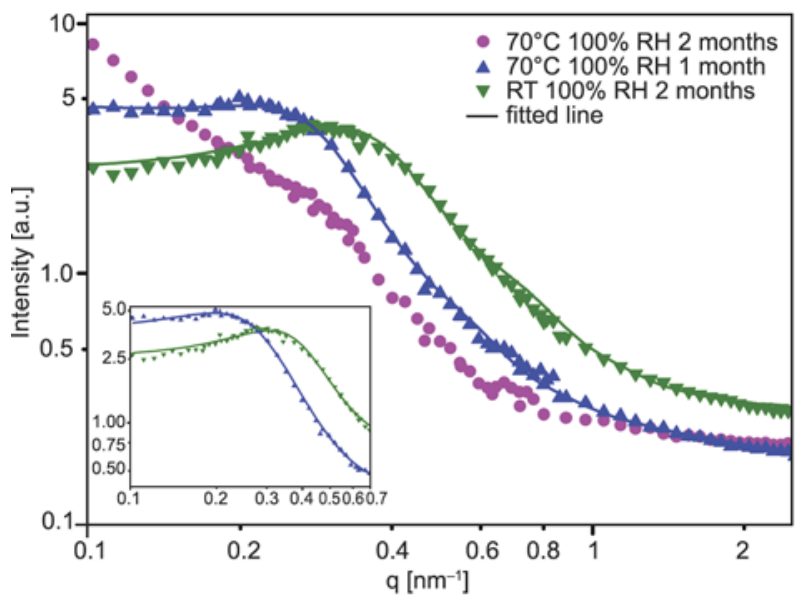

Figure 4. SANS data of Estane aged at $70^{\circ} \mathrm{C}$ in wet air for 1 and 2 months, as well as at RT in wet air for 2 months, the solid lines are the fitting results by DAB-PY model. The inset shows the fitting results by TS model.

that the scattering from PUs based on poly(butadiene)diol, 4,4'-diphenylmethane diisocyanate and poly(oxypropylene) triol can be adequately described using the Debye, Anderson and Brumberger (DAB) model for the hard domain shape. Although this is not a form factor of a compact object, in combination with the hard sphere interdomain structure factor it described reasonably well the scattering data, presumably because the right asymptotical behavior of the DAB model in the measured $q$ interval. The $\mathrm{DAB}$ model for random two-phase morphology is written by Equation (1):

$P(q)=\frac{1}{\left(1+a_{\text {corr }}^{2} q^{2}\right)^{2}}$

where $a_{\text {cor }}$ is correlation length. It represents the length over which the structural correlation decays. This model assumes smooth interfaces between the phases. The HSs content of Estane is low and consequently the hard-domains are much smaller than the chords crossing the soft and hard domains, therefore $a_{\text {cor }}$ can be considered as an approximation of the average hard domain size $[11,12]$. The formula of the Percus-Yevick (PY) type for the interference factor, applicable for hard sphere interaction, is shown in Equation (2):

$S(q)=\frac{1}{1+\frac{24 v G(A, v)}{A}}$

where

$A=2 q R_{\mathrm{HS}}$ 


$$
\begin{array}{ll}
G=\frac{\alpha}{A^{2}}(\sin A-A \cos A)+\frac{\beta}{A^{3}}\left[2 A \sin A+\left(2-A^{2}\right) \cos A-2\right]+\frac{\gamma}{A^{5}}\left\{-A^{4} \cos A+4\left[\left(3 A^{2}-6\right) \cos A+\left(A^{3}-6\right) \sin A+6\right]\right\} & \xi=\left[\frac{\left(\frac{a_{2}}{c_{2}}\right)^{1 / 2}}{2}+\frac{c_{1}}{4 c_{2}}\right]^{-1 / 2} \\
\alpha=\frac{(1+2 v)^{2}}{(1-v)^{4}} & \xi=2 \pi\left[\frac{6 v\left(1+\frac{v}{2}\right)^{2}}{(1-v)^{4}}\right. \\
\left.\beta=-\frac{\left(\frac{a_{2}}{c_{2}}\right)^{1 / 2}}{2}-\frac{c_{1}}{4 c_{2}}\right]^{-1 / 2}
\end{array}
$$

$R_{\mathrm{HS}}$ and $v$ denote the hard-sphere interaction radius and volume fraction, respectively [13]. The first strong peak in the PY structure factor is related to a preferential distance between adjacent hard domains. Herein, we take the DAB plus PY as an approximate model to fit the scattering intensities by Equation (3):

$$
I(q)=A \cdot P\left(q, a_{\mathrm{cor}}\right) \cdot S\left(q, R_{\mathrm{HS}}, v\right)+I_{\mathrm{B}}
$$

where $A$ is a scale factor, and the background intensity, $I_{\mathrm{B}}=A_{1}+A_{2} q^{4}$, accounts for the incoherent scattering and for large inhomogeneities, herein $A_{1}$ and $A_{2}$ are adjustable parameters. The fitted results are shown in Table 1. Good agreement is found between the measured data and the model function, except for the sample aged at $70^{\circ} \mathrm{C}$ for 2 months in wet air. Since the presence of separated and uniform HS domains is clearly an oversimplification, the scattering data were also fitted to Teubner-Strey (TS) model, which, according to Equations (4)-(6) describes a random two phase structure with locally lamellar order:

$$
I(q)=\frac{1}{a_{2}+c_{1} q^{2}+c_{2} q^{4}}+b
$$

Table 1. Structural parameters obtained from SANS data on aged Estane 5703 samples swollen by d-toluene by curve-fitting using the DAB-PY model and TS model

\begin{tabular}{|l|r|r|c|c|c|}
\hline \multirow{2}{*}{ Sample } & \multicolumn{3}{|c|}{ DAB-PY model } & \multicolumn{2}{c|}{ TS model } \\
\cline { 2 - 6 } & $\begin{array}{c}\mathbf{a}_{\text {cor }} \\
{[\mathbf{n m}]}\end{array}$ & $\begin{array}{c}\text { RHS } \\
{[\mathbf{n m}]}\end{array}$ & $\mathbf{v}$ & $\begin{array}{c}\boldsymbol{\xi} \\
{[\mathbf{n m}]}\end{array}$ & $\begin{array}{c}\mathbf{D} \\
{[\mathbf{n m}]}\end{array}$ \\
\hline Original & 2.3 & 8.4 & 0.15 & 6.1 & 18.2 \\
\hline $70^{\circ} \mathrm{C} 2$ months dry air & 2.5 & 8.8 & 0.12 & 5.9 & 20.1 \\
\hline RT 2 months 100\% RH & 2.3 & 8.3 & 0.15 & 6.0 & 18.0 \\
\hline $70^{\circ} \mathrm{C} \mathrm{1} \mathrm{month} 100 \% \mathrm{RH}$ & 3.8 & 10.6 & 0.15 & 7.0 & 25.9 \\
\hline
\end{tabular}

where $b$ is a background and $a_{2}, c_{1}$, and $c_{2}$ are composition-dependent coefficients, related to two characteristic lengths, $D$ and $\xi$, which appear in the spatial correlation function of the system [14]. $D$ represents a quasi-periodic repeat distance of hard domains, and $\xi$ is the correlation length. Hydrogels containing two phases and aqueous solutions of short chain surfactants often show such structure $[15,16]$. For our samples, the TS model gives good fit only over a restricted $q$ region from 0.1 to $0.7 \mathrm{~nm}^{-1}$, indicating that it does not describe fully the polymer structure on the length scale below $10 \mathrm{~nm}$. The characteristic periodicity or interdomain spacing is nevertheless well captured by this model. The fitted results are shown in Table 1. All the data was fitted by SASfit software [17].

\section{Results}

\subsection{Behavior in dry air}

The $I(q)$ curves of Estane 5703 aged in dry air at $R T$ and $70^{\circ} \mathrm{C}$ for 2 months are shown in Figure 3. The sample aged in dry air at RT is further referred as the original sample. A distinct interference peak is observed at $q=0.3 \mathrm{~nm}^{-1}$, which shifts with increasing aging temperature, towards smaller $q$-values, indicating increase of the interdomain distance. After aging at $70^{\circ} \mathrm{C}$ for 2 months in dry air, $R_{\mathrm{HS}}$ increases from 8.4 to $8.8 \mathrm{~nm}$ and $a_{\text {cor }}$ increases from 2.3 to $2.5 \mathrm{~nm} ; D$ increases from 18.2 to $20.1 \mathrm{~nm}$ and $\xi$ decreases from 6.1 to $5.9 \mathrm{~nm}$. These results indicate that the hard domain size keeps nearly unchanged while the distance between adjacent hard domains increases. $2 R_{\mathrm{HS}}$ and $\mathrm{D}$ are the characteristic distance and the average quasi-periodic distance of adjacent HS domains, in the two models, respectively. All samples exhibit a broad GPC peak (see Figure 5). Exposition of Estane to dry air at $70^{\circ} \mathrm{C}$ causes a small shift of the GPC peak to higher elution volume which is equivalent to shift of its molec- 


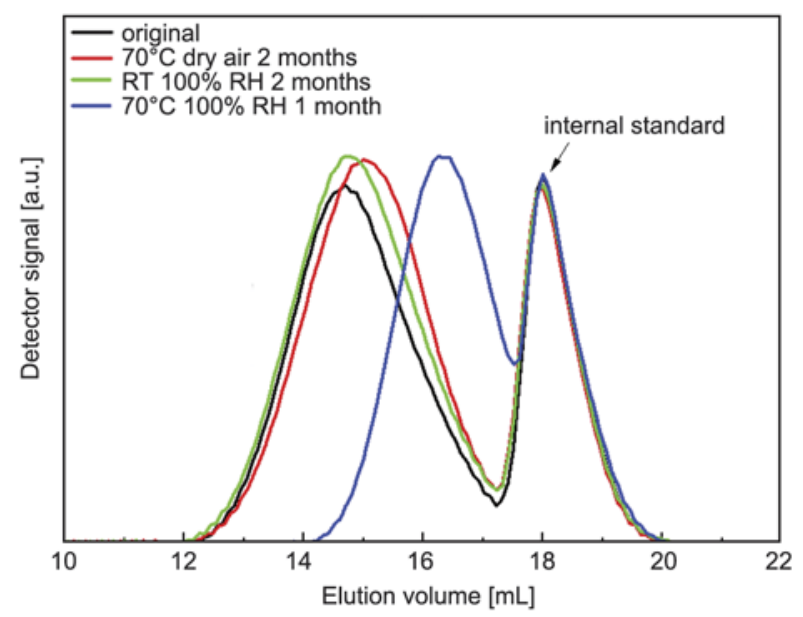

Figure 5. GPC curves for Estane aged at different environmental conditions

ular weight distribution to somewhat smaller values.

\subsection{Behavior in wet air}

The $I(q)$ curves of the samples aged at $R T$ and $70^{\circ} \mathrm{C}$ for 1 and 2 months in wet air are shown in Figure 4. The scattering curve and the fitted parameters keep nearly unchanged for the sample after aging at $R T$ in wet air for 2 months. At elevated temperature, $70^{\circ} \mathrm{C}$, however, a strong change of the sample structure is seen. After 1 month, the interference peak shifts to $q=0.2 \mathrm{~nm}^{-1}$, reflecting a significant increase in spacing between the discrete domains. Fitting by the aforementioned models, the structural parameters develop as follows: after 1 month, at $70^{\circ} \mathrm{C}$ and $100 \% \mathrm{RH}, a_{\text {cor }}$ increases from 2.3 to $3.8 \mathrm{~nm}$ and $R_{\mathrm{HS}}$ increases from 8.4 to $10.6 \mathrm{~nm}$; $\xi$ increases from 6.1 to $7.0 \mathrm{~nm}$ and $D$ increases from 18.2 to $25.9 \mathrm{~nm}$. Further treatment at $70^{\circ} \mathrm{C}$ in wet air for 2 months leads to a drastic change of the structure. The scattering at small $q$ values becomes strong, which indicates the appearance of a new population of scatters with the characteristic sizes above $100 \mathrm{~nm}$. The domains of HSs are still observable from the interference peak, however the model fits are no longer accurate due to the strong forward scattering. It appears that during this treatment the microstructure is badly destroyed, and, most importantly, the structure looses its homogeneity on the length scale above $100 \mathrm{~nm}$. As shown in Figure 5, exposition of Estane to wet air at $R T$ does not show any effect on position and width of the GPC peak. However, the peak is shifted considerably under exposition of the material to wet air at elevated temperature $\left(70^{\circ} \mathrm{C}\right)$ which signifies a shift of molecular weight distribution of polymer to much lower values.

\section{Discussion}

The hard domain size keeps nearly unchanged and the distance between hard domains increases for the samples aged at $70^{\circ} \mathrm{C}$ in dry air for 2 months, which could be explained by the remixing of small HSs into the soft phase. The glass transition temperature of hard domains in Estane is around $70^{\circ} \mathrm{C}$, and at this temperature part of HSs and SSs are remixed. The rather broad scattering peak shows a wide distribution in the size of the HS and SS domains. The shorter HSs can dissolve within the SSs if their length is below the critical length for microphase separation [4]. Therefore the aging may preferentially destroy the smaller HSs domains, which could result in the shift of the peak to low q-value and the increase of the average hard domain distance.

Our experiments reveal that the combined effects of temperature $\left(70^{\circ} \mathrm{C}\right)$ and humidity $(100 \% \mathrm{RH})$ strongly modify the nanoscale structure of Estane 5703. It can be inferred that the hydrolysis at $70^{\circ} \mathrm{C}$ is the main reason for the changes of hard domains distance and size. The ester group is most susceptible to hydrolysis, which reverts RCOOR' to polymeric acid $(\mathrm{RCOOH})$ and polymeric alcohol $\left(\mathrm{R}^{\prime} \mathrm{OH}\right)[18$, 19]. This is a chain scission reaction inducing the decrease of the molecular weights of the polymer chains. The GPC results shown in Figure 5 and parameters determined from them are in agreement with this observation (Table 2). Compared with the original sample, the molecular weight of Estane aged at $70^{\circ} \mathrm{C}$ in wet air for 1 month decreased about 9-fold, while the molecular weights of Estane aged at $R T$ in wet air and $70^{\circ} \mathrm{C}$ in dry air for 2 months have a little drop. Thompson et al. [20] also proved that the molecular weights for Estane aged in wet air decreased strongly after 20 days. Moreover, we

Table 2. Molecular weight distribution parameters obtained from GPC data on aged Estane 5703 samples: $M_{\mathrm{n}}$ and $M_{\mathrm{w}}$ denote number- and weight-average (polystyrene equivalent) of molecular weight, respectively

\begin{tabular}{|l|c|c|c|}
\hline \multicolumn{1}{|c|}{ Sample } & $\begin{array}{c}\mathbf{M}_{\mathbf{n}} \\
{[\mathbf{g} / \mathbf{m o l}]}\end{array}$ & $\begin{array}{c}\mathbf{M}_{\mathbf{w}} \\
{[\mathbf{g} / \mathbf{m o l}]}\end{array}$ & $\mathbf{M}_{\mathbf{w}} / \mathbf{M}_{\mathbf{n}}$ \\
\hline Original & 32000 & 104000 & 3.3 \\
\hline $70^{\circ} \mathrm{C} 2$ months dry air & 26700 & 113000 & 4.2 \\
\hline RT 2 months $100 \%$ RH & 33000 & 106000 & 3.2 \\
\hline $70^{\circ} \mathrm{C} 1$ month $100 \%$ RH & 3600 & 7900 & 2.2 \\
\hline
\end{tabular}


found that part of the Estane samples aged at $70^{\circ} \mathrm{C}$ and $100 \%$ RH were dissolved in toluene, while no obvious dissolution for the samples aged in dry air was observed. This appears to be the consequence of the hydrolysis of the ester links and decrease of the molecular weight [18].

The increase in hard domains distance can be mainly attributed to the chain scission of SSs. It is reported that the ester segments are more than an order of magnitude more susceptible to hydrolytic cleavage than the urethane [21]. This means the chain scission would induce a looser structure in SSs, which in turn, may lengthen the distance between adjacent hard domains. The increase in hard domain size is also related with the hydrolysis. First, it is energetically favourable for the SSs and HSs not to mix. The phase separation process is inhibited by steric and mobility constraints. Second, the SSs mobility of the hydrolyzed Estane is increased due to the decrease of the molecular weights after hydrolysis. Hence the organization of the HSs into domains becomes easier, and the HS domains incline to grow bigger than those of the non-aged or dry-aged samples. This analysis is in accordance with the literature, which reported that the increased molecular weights and decreased chain mobility of nitroplasticized Estane caused by branching undergoes a less degree of phase separation [22]. Furthermore, the tensile strength of the samples aged at $70^{\circ} \mathrm{C}$ in wet air $(75 \% \mathrm{RH})$ for 27 and 59 days was reduced by 58 and $93 \%$ respectively with respect to the corresponding values measured before aging [3]. Hence the increase of hard domain size and distance correlates straightly with the chemical changes and the change of the mechanical properties of Estane. In summary,

\begin{tabular}{|c|c|c|}
\hline $\begin{array}{l}0 \\
0 \\
0\end{array}$ & $\begin{array}{c}2 \text { months } \\
\text { The domains dissolve } \\
\mathrm{R}_{\mathrm{HS}}=8.8 \mathrm{~nm} \\
\mathrm{D}=20.1 \mathrm{~nm}\end{array}$ & $\begin{array}{c}1 \text { month } \\
\mathrm{R}_{\mathrm{HS}}=10.6 \mathrm{~nm} \\
\mathrm{D}=25.9 \mathrm{~nm} \\
\text { Hydrolysis is the reason. } \\
2 \text { months } \\
\text { The microstructure is badly } \\
\text { destroyed. }\end{array}$ \\
\hline 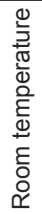 & $\begin{array}{c}\text { DAB-PY model: } \\
\begin{array}{c}\mathrm{R}_{\mathrm{HS}}=8.4 \mathrm{~nm} \\
\mathrm{a}_{\mathrm{cor}}=2.3 \mathrm{~nm} \\
\\
\text { TS model } \\
\mathrm{D}=18.2 \mathrm{~nm} \\
\xi=6.1 \mathrm{~nm}\end{array}\end{array}$ & $\begin{array}{l}\text { Hard domain size and distance } \\
\text { keep nearly unchanged. }\end{array}$ \\
\hline & Dry air & Wet air $(100 \% \mathrm{RH})$ \\
\hline
\end{tabular}

Figure 6. Summary diagram of the microstructural changes of Estane 5703 at various aging conditions the microstructural changes of the studied Estane 5703 are shown in Figure 6.

\section{Conclusions}

Microstructures of Estane swollen in deuterated toluene after aging at $70^{\circ} \mathrm{C}$ in dry air and wet air have been studied by SANS technique. The hard domain size keeps nearly unchanged and the distance between hard domains increases for the samples aged in dry air for 2 months. Both the domain sizes and their distances, analyzed by DAB-PY and TS models, are increased for the humidity-aged sample at $70^{\circ} \mathrm{C}$ for 1 month. Further treatment at $70^{\circ} \mathrm{C}$ in wet air for 2 months leads to restructuring or degradation of the sample observable at a larger length scale, with characteristic size above $100 \mathrm{~nm}$. The combined effects of temperature and humidity strongly modify the nanoscale structure of Estane 5703. The hydrolysis of ester links at $70^{\circ} \mathrm{C}$ that causes a decrease of average molecular weight of the polymer chains is the main reason for these changes. This study contributes to understanding the structure-property correlations of polyurethanes in different environments.

\section{Acknowledgements}

This work was supported by the National Natural Science Foundation of China under grant Nos. 11205137, 11079043, and 11302199, and by project KMR12-1-2012-0226 granted by the National Development Agency (NDA) of Hungary. We thank the many useful suggestions of the anonymous referees.

\section{References}

[1] Prisacariu C.: Polyurethane elastomers: From morphology to mechanical aspects. Springer, Wien (2011).

[2] Mang J. T., Peterson P. D., Orler E. B., Wrobleski D. A., Langlois D. A., Espada L. I., Hjelm R. P.: Smallangle neutron scattering study of a thermally aged, segmented poly(ester urethane) binder. Neutron News, 14, 26-28 (2003). DOI: $10.1080 / 10448630308218510$

[3] Orler E. B., Wrobleski D. A., Smith M. E.: Hydrolytic degradation of Estane 5703. Los Alamos National Laboratory, US, No. LA-UR-99-1383 (1999).

[4] Koberstein J. T., Galambos A. F., Leung L. M.: Compression-molded polyurethane block copolymers. 1 . Microdomain morphology and thermomechanical properties. Macromolecules, 25, 6195-6204 (1992). DOI: $10.1021 / \mathrm{ma} 00049 \mathrm{a} 017$ 
[5] Krakovský I., Bubeníková Z., Urakawa H., Kajiwara K.: Inhomogeneous structure of polyurethane networks based on poly(butadiene)diol: 1 . The effect of the poly (butadiene)diol content. Polymer, 38, 3637-3643 (1997). DOI: 10.1016/S0032-3861(96)00897-X

[6] Krakovský I., Urakawa H., Kajiwara K.: Inhomogeneous structure of polyurethane networks based on poly(butadiene)diol: 2. Time-resolved SAXS study of the microphase separation. Polymer, 38, 3645-3653 (1997). DOI: 10.1016/S0032-3861(96)00898-1

[7] Koberstein J. T., Russell T. P.: Simultaneous SAXSDSC study of multiple endothermic behavior in polyether-based polyurethane block copolymers. Macromolecules, 19, 714-720 (1986).

DOI: $10.1021 / \mathrm{ma} 00157 \mathrm{a} 039$

[8] Blundell D. J., Eeckhaut G., Fuller W., Mahendrasingam A., Martin C.: Real time SAXS/stress-strain studies of thermoplastic polyurethanes at large strains. Polymer, 43, 5197-5207 (2002). DOI: $10.1016 / \mathrm{S} 0032-3861(02) 00386-5$

[9] Mang J. T., Hjelm R. P., Orler E. B., Wrobleski D. A.: Small-angle neutron scattering of a solvent-swollen segmented polyurethane as a probe of solvent distribution and polymer domain composition. Macromolecules, 41, 4358-4370 (2008). DOI: $10.1021 / \mathrm{ma} 800015 \mathrm{~g}$

[10] Keiderling U.: The new 'BerSANS-PC' software for reduction and treatment of small angle neutron scattering data. Applied Physics A, 74, 1455-1457 (2002). DOI: $10.1007 / \mathrm{s} 003390201561$

[11] Debye P., Anderson R., Brumberger H.: Scattering by an inhomogeneous solid. II. The correlation function and its application. Journal of Applied Physics, 28, 679-683 (1957).

DOI: $10.1063 / 1.1722830$

[12] Linliu K., Chen S-A., Yu T. L., Lin T-L., Lee C-H., Kai J-J., Chang S-L., Lin J. S.: A small-angle X-ray scattering study of microphase separation transition of polyurethanes: Effect of hard segments. Journal of Polymer Research, 2, 63-70 (1995).

DOI: $10.1007 / \mathrm{BF} 01493435$

[13] Percus J. K., Yevick G. J.: Analysis of classical statistical mechanics by means of collective coordinates. Physical Review, 110, 1-13 (1958).

DOI: 10.1103/PhysRev.110.1
[14] Li W., Ryan A. J., Meier I. K.: Morphology development via reaction-induced phase separation in flexible polyurethane foam. Macromolecules, 35, 5034-5042 (2002). DOI: $10.1021 / \mathrm{ma} 020035 \mathrm{e}$

[15] Krakovský I., Székely N.: Small-angle neutron scattering study of nanophase separated epoxy hydrogels. Journal of Non-Crystalline Solids, 356, 368-373 (2010). DOI: $10.1016 /$ j.jnoncrysol.2009.11.037

[16] D’Arrigo G., Giordano R., Teixeira J.: Temperature and concentration dependence of SANS spectra of aqueous solutions of short-chain amphiphiles. The European Physical Journal E, 29, 37-43 (2009). DOI: $10.1140 /$ epje/i2008-10447-7

[17] Kohlbrecher J.: SASfit: A program for fitting simple structural models to small angle scattering data. Paul Scherrer Institute, Laboratory for Neutron Scattering (2011).

[18] Gardner R. J., Martin J. R.: Effect of relative humidity on the mechanical properties of poly(1,4-butylene terephthalate). Journal of Applied Polymer Science, 25, 2353-2361 (1980). DOI: $10.1002 / a p p .1980 .070251021$

[19] Salazar M. R., Lightfoot J. M., Russell B. G., Rodin W. A., Mccarty M., Wrobleski D. A., Orler E. B., Spieker D. A., Assink R. A., Pack R. T.: Degradation of a poly (ester urethane) elastomer. III. Estane 5703 hydrolysis: Experiments and modeling. Journal of Polymer Science: Part A: Polymer Chemistry, 41, 1136-1151 (2003). DOI: $10.1002 /$ pola. 10656

[20] Thompson D. G., Osborn J. C., Kober E. M., Schoonover J. R.: Effects of hydrolysis-induced molecular weight changes on the phase separation of a polyester polyurethane. Polymer Degradation and Stability, 91, 3360-3370 (2006).

DOI: 10.1016/j.polymdegradstab.2006.05.019

[21] Fambri L., Penati A., Kolarik J.: Synthesis and hydrolytic stability of model poly(ester urethane ureas). Angewandte Makromolekulare Chemie, 228, 201-219 (1995).

DOI: 10.1002/apmc.1995.052280116

[22] Orler E. B., Wrobleski D. A., Cooke D. W., Bennett B. L., Smith M. E., Jahan M. S.: Thermal aging of nitroplasticized Estane 5703. Los Alamos National Laboratory, US, No. LA-UR-02-1315 (2002). 